Street Art y videojuegos: el caso de Invader

Israel Márquez

Universitat Oberta de Catalunya (España) 



\title{
Street Art y videojuegos: el caso de Invader
}

\section{Street Art and Video Games: The case of Invader}

\author{
Israel Márquez \\ Universitat Oberta de Catalunya (España) \\ isravmarquez@gmail.com
}

Fecha de recepción: 14 de marzo de 2018

Fecha de aceptación: 27 de marzo de 2020

\section{Resumen}

El presente artículo analiza las relaciones entre street art y videojuegos como un ejemplo concreto de nueva práctica artística en el espacio urbano. Para ilustrar esta relación analizamos el proyecto artístico del artista urbano francés Invader, quien ha construido su identidad artística a partir de la apropiación material de los famosos personajes del videojuego Space Invaders y su traslado del espacio digital de la pantalla al espacio público de la calle.

Palabras clave: Street art; Graffiti; Videojuegos; Cultura digital; Espacio público; Semiótica.

\begin{abstract}
The article analyzes the relationship between street art and video games as a new type of art practice in urban space. To illustrate this relationship, we analyze the work of the French street artist known as Invade. This artist has appropriated the characters from Space Invaders classic video game to build his artistic identity, transferring them from the digital space of the screen to the public space of the street.
\end{abstract}

Key Words: Street art; Graffiti; Video games; Digital culture; Public space; Semiotics. 


\section{INTRODUGGIÓN}

El término street art comenzó a circular entre mediados y finales de la década de 1990 como una forma de referirse al trabajo de una serie de artistas callejeros que empezaron a adoptar nuevos materiales, técnicas y métodos en sus intervenciones en el espacio urbano (Amstrong, 2019). El street art constituye actualmente una de las manifestaciones paradigmáticas de la cultura visual contemporánea (Mirzoeff, 2003; Irvine, 2012) y está siendo utilizado cada vez más como medio de expresión artística capaz de llegar y afectar a amplias capas de la población. De hecho, como han señalado algunos autores (Christensen y Thor, 2017; Amstrong, 2019), una de las diferencias entre el street art y el graffiti es que el street art invita a todos a ser su público, esto es, se dirige al público en general y a menudo comunica mensajes explícitos, mientras que el graffiti se concibe más como una especie de lengua vernácula tribal, un idioma codificado de forma "críptica" (Armstrong, 2005) que "en un principio sólo alcanzan a entender los iniciados en la comunidad emocional de las bandas y grupos juveniles del espacio urbano familiar" (López, 1998, p. 176), algo que se observa claramente en formas como los throw-ups y el wildstyle.

En este artículo nos centraremos en un caso específico de street art, el del popular artista francés Invader, quien a través de la apropiación lúdica de los populares marcianitos del videojuego Space Invader ha conseguido crear una de las formas de expresión artística callejera más originales de este movimiento. El caso de Invader nos permite profundizar en un aspecto muy concreto y poco estudiado dentro de las complejas relaciones entre prácticas artísticas y ciudad: el de la apropiación lúdica del espacio público a través de un arte directamente inspirado en el mundo de los videojuegos, tal y como propone este artista. Se estudia, por tanto, las relaciones entre videojuegos y street art y cómo el mundo de los videojuegos -representado en este caso por los famosos personajes del videojuego Space Invaders-, ha conseguido trasladarse del espacio videolúdico de la pantalla al espacio público de nuestras ciudades contemporáneas.

\section{2. ¿QUÉ ES EL STREET ART?}

Como decíamos antes, el término street art comenzó a circular entre mediados y finales de la década de 1990 (Amstrong, 2019) como una forma de referirse a nuevas tendencias en intervención artística urbana, tales como el poster art, el stencil art, el mosaic art, etc. Para algunos autores, el street art es algo que va más allá del graffiti, de ahí que también se le conozca como "neo graffiti" o "postgraffiti" (Ganz, 2004; Reinecke, 2007), una forma evolucionada de graffiti que no se limita al empleo del clásico bote de aerosol, sino que incluye una amplia variedad de técnicas, materiales y métodos, desde plantillas hasta pegatinas, carteles adhesivos, recortes 
de papel, azulejos de cerámica, pinceles, rodillos, etc. Otros autores, sin embargo, juzgan incorrecto el uso de términos como "postgraffiti" para referirse al street art, puesto que el prefijo "post" indica "después de", pero la mayoría de veces implica el fin de lo antecedido: "El uso del término postgraffiti es muy confuso, porque el graffiti no ha acabado, no concluyó dando paso al arte urbano. Sigue vigente en nuestros días y aunque influyó sobre el street art, y son movimientos paralelos, no son lo mismo" (Fernández Herrero, 2018, p. 31).

El street art es, ante todo, apropiación del espacio público, y en esto resulta muy similar al graffiti, pues ambas son formas invasivas de creación de letras e imágenes en el espacio público (Amstrong, 2019). De alguna manera, como decía Michel de Certeau (1999), todos nos apropiamos de la ciudad cuando caminamos, entendiendo que el andar es un espacio de enunciación que supone un proceso de apropiación del sistema topográfico por parte del peatón. Pero en el street art esta apropiación deja una huella visual o verbovisual concreta, que permanece durante días o semanas en el espacio urbano y que es el índice -en el sentido semiótico del término- de que alguien estuvo allí y se apropió materialmente del espacio urbano a través de una intervención artística.

El street art permite interaccionar con el entorno y reinterpretarlo creativamente. El street art tiene que ver con mirar las calles desde una óptica diferente. Tiene que ver con escoger una pared, un vagón de tren, un cubo de basura, un semáforo, una señal de tráfico o un poste de luz y adaptarlos a nuestros intereses, apropiarse creativamente de ellos, descubriendo nuevas oportunidades y posibilidades expresivas allí donde antes no las había, o simplemente no eran percibidas. Es, por tanto, un proceso de observación, imaginación y aplicación que inunda nuestras ciudades de signos visuales y verbales y que contribuye, junto con otros signos e imágenes, al dinamismo, energía y vitalidad urbanas.

Irvine (2012, p. 1) define el street art como una forma global y local (glocal), post-fotográfica, post-Internet, post-mediática, intencionadamente efímera pero documentada y compartida casi obsesivamente gracias a la fotografía digital e Internet, y que constantemente se apropia y remezcla imágenes, estilos y técnicas procedentes de una variedad de fuentes posibles. Esto hace del street art un paradigma del "todo vale" y el hibridismo postmoderno, donde, como señala Lipovetsky (2002, p. 121), "se vuelven preeminentes el eclecticismo, la heterogeneidad de los estilos en el seno de una misma obra, lo decorativo, lo metafórico, lo lúdico, lo vernacular, la memoria histórica. El posmodernismo se revela contra la unidimensionalidad del arte moderno y reclama obras fantasiosas, despreocupadas, híbridas". Desde la variedad de técnicas utilizadas (stickers, stencils, azulejos, carteles adhesivos, etc.), los lugares objeto de intervención (paredes, señales de tráfico, vagones de tren, placas urbanas, etc.), o la diversidad de imágenes y temáticas tratadas (desde sucesos políticos hasta iconos mediáticos o personajes de videojuegos), el street art se define 
como una forma visual fundamentalmente híbrida, ecléctica y heterogénea, que nos habla del mundo contemporáneo, sus contradicciones y su complejidad. ${ }^{1}$

El street art es un fenómeno estrechamente ligado a Internet y la tecnología de banda ancha. A partir de finales de la década de 199., Internet cambió la forma de intercambiar la información y revolucionó la distribución y el acceso al street art gracias a que las obras podían subirse en cuestión de minutos para que todo el mundo las viera (Amstrong, 2019). Internet, como han sugerido algunos artistas y autores (Abarca, 2010), se convirtió en el "nuevo metro" del street art, el soporte que, al igual que hizo el metro con el graffiti, ha conseguido llevar las obras de una punta a otra de la escena, una escena ya no circunscrita a una ciudad sino entendida como un fenómeno global. Como señala el artista James Powderly en este sentido: "[...] usamos Internet de la misma manera que los viejos artistas del graffiti usaban el metro. Ellos dejaban a los trenes la tarea de difundir sus obras por la ciudad, y nosotros usamos ahora estos vídeos e Internet para difundir nuestro trabajo por el mundo" (citado en Abarca, 2010). Así mismo, este "nuevo metro" que para el street art supone Internet, permite a los artistas conocer inmediatamente las reacciones del público ante su obra, así como la de otros artistas, lo cual ha aumentado el alcance de la competición y la notoriedad a una escala mundial (Ibid.).

\section{STREET ART, INTERTEXTUALIDAD Y VIDEOJUEGOS}

Además de ser una forma visual fundamentalmente híbrida, ecléctica y heterogénea, como decíamos en el apartado anterior, el street art es igualmente una forma visual intertextual que se inspira en diversos textos culturales, artísticos, políticos y mediáticos, y se apropia creativamente de ellos. Los personajes son un elemento fundamental del graffiti desde la década de 1970 (Amstrong, 2019), y el street art ha hecho de ellos un elemento fundamental de los artistas urbanos. Durante años, estos artistas se han servido de los personajes del cómic, los dibujos animados o el cine para crear sus obras y generar diversos intertextos (en forma de imágenes, palabras o estéticas que remiten a esos personajes y sus universos ficcionales) que reclaman nuestra atención y apelan a la "enciclopedia" (Eco, 1990) de los transeúntes.

En los últimos años, los videojuegos y algunos de sus característicos personajes han adquirido una importancia fundamental como nueva fuente de inspiración para el street art (Márquez y Tosca, 2017, pp. 105-120), como demuestra el éxito del artista parisino Invader y su apropiación lúdica del famoso videojuego Space Invaders. Aparte de ser uno de los negocios más lucrativos de la actualidad, los videojuegos

1 García Canclini (1990, p. 314) ya definía el graffiti como "un género constitucionalmente híbrido" y señalaba que los graffitis "constituyen una práctica que desde su nacimiento se ha desentendido del concepto de colección patrimonial, conformando un lugar de intersección entre lo visual y lo literario, lo culto y lo popular". 
forman una parte importante de la cultura contemporánea y ocupan un lugar cada vez más destacado en el imaginario social de mucha gente. Como resultado de una cada vez mayor omnipresencia de los videojuegos en la sociedad actual, hoy en día son varias las personas familiarizadas con personajes como Mario Bros, Lara Croft, Zelda, Sonic, Pac Man o los famosos marcianitos de Space Invaders, los cuales adquieren en la actualidad un estatus similar a otros personajes destacados de la cultura massmediática como Mickey Mouse, Los Simpson, Superman, Batman, Mafalda, o iconos del cine y la música popular como Marilyn Monroe, James Dean, The Beatles, Kurt Cobain, Bob Marley, etc. Al igual que estos personajes de la cultura popular, los personajes de videojuegos forman parte de un supersistema que se expande a través de diferentes productos culturales e incluso a través de varios objetos de la vida cotidiana, como pueden ser camisetas, calcetines, carpetas, cajas de cereales, estuches, sábanas, pegatinas, etc. El resultado es, según Marsha Kinder (1991), una "red de intertextualidad transmediática" que facilita el éxito global del personaje y del universo narrativo del que forma parte.

No extraña, pues, que la presencia de los videojuegos -sus personajes, imágenes, sonidos y gestos característicos- sea cada vez más notable en medios como el cine, la publicidad, la televisión, la música, el cómic o el videoclip, los cuales llevan años fijándose en su compañero lúdico e interactivo para apropiarse de algunas de sus características formales e incorporarlas a su propio lenguaje. En términos de adaptaciones, intertextualidad o "remediación" (Bolter y Grusin, 1999), los videojuegos se sitúan actualmente al mismo nivel que otros medios y ya no es posible hablar de estos conceptos sin incluir a los videojuegos, quienes se han convertido incluso en el punto de partida de estas relaciones y conexiones transmediáticas, como demuestran casos como el de Mario Bros, Sonic, Lara Croft o Pokémon.

En el caso del street art, el caso de Invader resulta paradigmático a la hora de analizar la influencia de los videojuegos en esta particular área artística y cultural. La diferencia de Invader con respecto a otros artistas urbanos es que este artista toma el mundo de los videojuegos como inspiración y principal referente a la hora de crear significado y proponer nuevas formas de lectura/escritura de los espacios urbanos. De ahí que en este texto se tome su obra como objeto de estudio a la hora de analizar las relaciones entre el street art y los videojuegos.

\section{STREET ART Y VIDEOJUEGOS: EL CASO DE INVADER}

Invader es un artista urbano francés que se define a sí mismo como un UFA, esto es, un Unidentified Free Artist o "Artista Libre No Identificado". El artista prefiere conservar su anonimato escondiéndose bajo el seudónimo de Invader y utilizando siempre una máscara cuando hace una entrevista o declaración pública. Invader justifica su anonimato señalando que su obra es más importarte que su verdadera identidad. 
Desde el año 1998, Invader lleva desarrollando un proyecto a larga escala conocido como Space Invaders y directamente inspirado en el popular videojuego del mismo nombre desarrollado por Toshihiro Nishikado veinte años antes. Space Invaders es uno de los títulos más importantes de la historia de los videojuegos y uno de los primeros en lograr un éxito comercial sin precedentes, tanto en Japón como en Estados Unidos. Tal fue el éxito de este videojuego en Japón que se generó una gran escasez de monedas, dado que eran utilizadas de manera compulsiva en las salas de máquinas recreativas. El gobierno nipón tuvo que cuadriplicar la producción de monedas de cien yenes para hacer frente a este problema (Kohler, 2015).

El objetivo del juego era muy simple: eliminar el mayor número de alienígenas o marcianitos invasores (los "invasores del espacio" del título) con un cañón laser y obtener así el mayor número de puntos posible. A medida que el jugador iba destruyendo a los marcianitos, éstos se iban acercando a la tierra de una forma más rápida, lo que exigía una mayor concentración y rapidez de reflejos del jugador a la hora de disparar y acabar con ellos. Tal es el tipo de jugabilidad propio de los denominados "juegos de disparos", "shotter" o "shoot'em up", un género extremadamente popular en los primeros años de los videojuegos y del que Space Invaders fue uno de sus títulos más famosos (Darley, 2002), llegando incluso a desatar un furor mundial por este tipo de juegos (Ryan, 2011). Los "shooters" requerían un alto grado de concentración y coordinación mano-ojo pues los tiempos de reacción eran mínimos debido a un ritmo de acción rápido y trepidante, lo que en su época constituyó una nueva y original forma de entretenimiento (Kohler, 2016).

El éxito de Space Invaders provocó el lanzamiento de nuevos juegos destinados a las salas de máquinas recreativas. La mayoría de ellos no eran sino variaciones sobre el tema del combate espacial y, de hecho, en la mayor parte de los casos se trataba de juegos "de disparos" o "de batalla". Como recuerda Manovich (2006, p. 322), estos primeros videojuegos partían de una temática muy concreta: se simulaba una suerte de combate aéreo y el espacio era uno de los personajes principales, de ahí que todos ellos llevaran la palabra "espacio" en sus títulos (SpaceWar, Computer Space, Space Invaders, etc.). Así mismo, como señala Kohler (2016), en el caso de Space Invaders, Nishikado se inspiró también en películas de temática espacial como Star Wars, muy popular en Estados Unidos por aquella época, pero también en series de animación espaciales que empezaron a ganar popularidad en Japón por las mismas fechas, como Uchū Senkan Yamato (Space Battleship Yamato).

Invader tomó Space Invaders como punto de partida para su proyecto artístico y como una forma original de trasladar este universo videolúdico del espacio rectangular de la pantalla al mundo físico y tangible. En su página web, Invader explica que la idea detrás de su proyecto es liberar el arte de sus espacios habituales, los museos y las instituciones, para acercarlo a la gente. Esto lo logra apropiándose de las figuras de los famosos marcianitos de Space Invaders por considerar que son "los iconos perfectos de nuestro tiempo, un tiempo en el que las tecnologías 
digitales son el latido de nuestro mundo"2. Estos marcianitos son ya parte de la historia y la cultura de los videojuegos, y son fácilmente reconocibles no sólo por las generaciones que físicamente vieron y jugaron a Space Invaders en las máquinas recreativas y consolas de la época, sino también por aquellas nuevas generaciones de jugadores que pueden disfrutar hoy de este tipo de títulos clásicos a través de formas de retrogaming como los emuladores gratuitos y los remakes (Camper, 2009; PérezGómez, 2009).3

Los marcianitos de Space Invaders actúan para Invader a modo de seudónimo, y le permiten llevar a cabo su "invasión" del espacio público a partir de una práctica artística muy interesante: el empleo de azulejos para formar mosaicos que simulan o remedian de una forma material la pixelización característica de los primeros videojuegos. Los azulejos le sirven a Invader como una herramienta adecuada para dar una apariencia material y "artesanal" a la estética pixelada del videojuego Space Invaders, una estética común a todos los videojuegos de la era de los 8 bits. Es su forma de trasladar o "traducir" el espacio digital del videojuego al espacio material de la calle.

Invader no sólo materializa en el espacio urbano la estética de los populares personajes del videojuego sino su propio objetivo: invadir la tierra. Invader ha llevado su "invasión! a varias ciudades del planeta, desde Los Ángeles hasta Hong Kong, pasando por Barcelona y, por supuesto, París, su ciudad de residencia. En su página web puede consultarse un mapa interactivo ${ }^{4}$ donde documenta detalladamente el número de ciudades invadidas hasta la fecha, así como el número de invasiones realizadas (en el momento de escribir este artículo, la página contabiliza 3.861 invasiones distribuidas entre 79 ciudades). Una vez que accedemos al mapa, los marcianitos caen directamente desde la parte de arriba de la pantalla y se posicionan rápidamente sobre aquellas ciudades que ya han sido invadidas. Pulsando en los iconos accedemos a fotografías que nos muestran de manera visual el tipo de intervención realizada, junto a una breve descripción textual que incluye información sobre el número de invasiones realizadas en esa ciudad, las "olas de invasión" (las veces que Invader ha vuelto a esa ciudad para realizar nuevas invasiones), y los puntos obtenidos tras la misión. Si consultamos, por ejemplo, el caso de la ciudad de Nueva York, veremos que el artista ha realizado 219 invasiones en 8 olas de invasión, alcanzando con ello 6760 puntos.

\section{2 http://space-invaders.com/about/}

3 El retrogaming puede definirse como el culto a las plataformas antiguas y sus respectivos videojuegos, tanto de ordenador como de las consolas de 8-bits. Como señala Pérez-Gómez (2009, p. 233): "El retrogaming supone una autoreflexión por parte de los usuarios sobre el videojuego como medio cultural y de ocio, que conduce a intentar que los límites de una plataforma no vengan impuestos por los creadores de dichos soportes, sino por los usuarios de los mismos. Son éstos los que intentan definir los límites temporales, la caducidad o no de un formato, y si dichas plataformas están o no obsoletas".

4 http://space-invaders.com/world/ [02/02/2017]. 


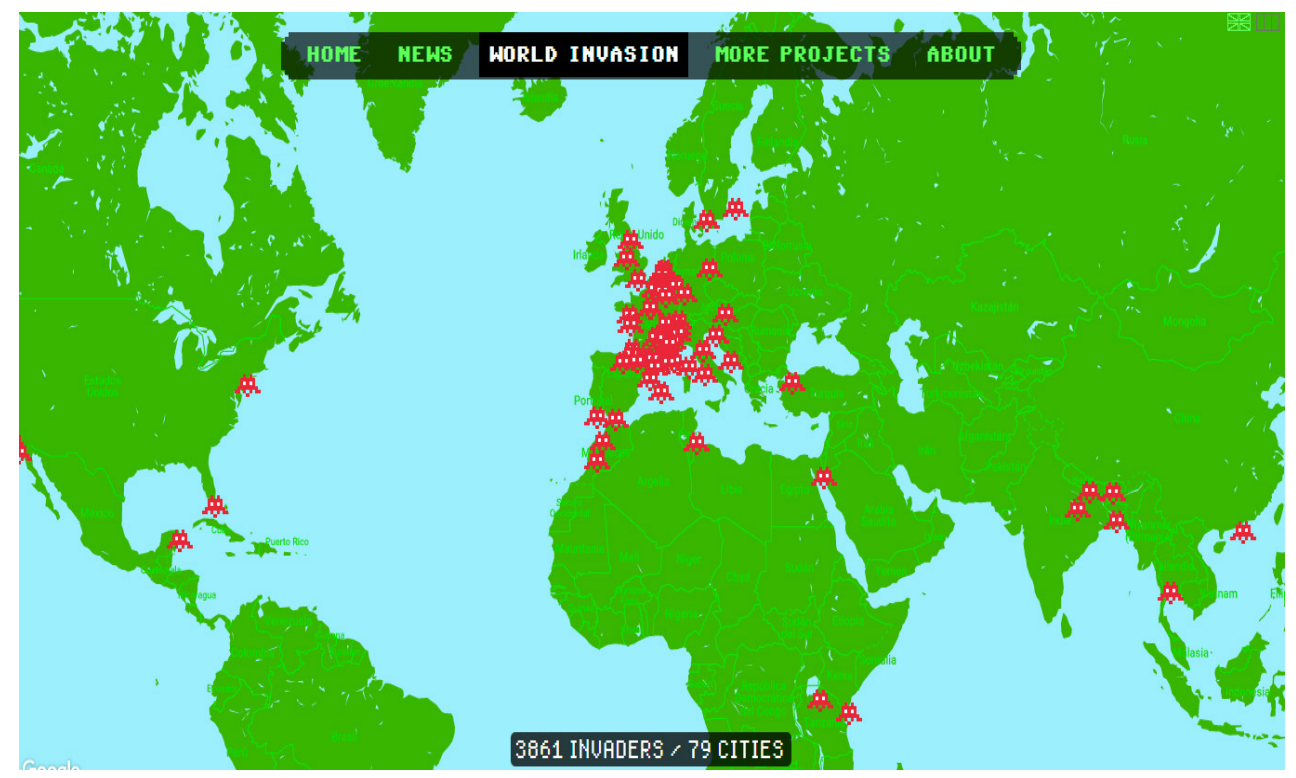

Imagen 1. Mapa de las invasiones realizadas por Invader hasta la fecha. Fuente: http://space-invaders.com/world/ [12/02/2020]

El trabajo de Invader muestra el carácter del artista urbano como artista "nómada", el cual genera, como apunta Irvine (2012, p. 19), un nuevo tipo de práctica artística: hacer obras en varias ciudades y documentarlas en tiempo real en la web. Estos artistas nómadas de street art imaginan la ciudad global como una superficie distribuida en la que marcar e inscribir intervenciones visuales que funcionan tanto a nivel local como global (glocal). El acto local de realizar una intervención visual en un lugar concreto puede verse desde cualquier otro lugar del mundo, y ser documentado, archivado, comparado, imitado o remezclado por diferentes usuarios y en diversas redes. El artista de street art es, en este sentido, un ejemplo del "ciudadano nómada" descrito por autores como Urry (2005), un sujeto que se mueve y circula por una sociedad crecientemente móvil y que siempre va acompañado de tecnologías y dispositivos igualmente móviles, como tablets, cámaras digitales o teléfonos móviles. Estos aparatos tecnológicos nos permiten interactuar diariamente con otros agentes y dispositivos móviles, convirtiendo a nuestra sociedad en una "sociedad móvil" (Urry, 2005) que es la a vez una "sociedad red" (Castells, 2005), un entramado sociocultural hecho de redes, interacciones y movimientos locales y globales, físicos y virtuales.

Al otorgar puntos a sus intervenciones, Invader concibe la ciudad como una especie de videojuego cuyo objeto es invadir el máximo número posible de lugares. La ciudad, en cierto modo, se "gamifica", en el sentido que se le incorporan técnicas, estéticas, y dinámicas propias de los videojuegos, un proceso conocido como 
"gamificación". ${ }^{5}$ Así, espacios urbanos en principio naturalizados (y para muchos insignificantes) como muros, esquinas, placas de nombres de calle, o señales de tráfico, adquieren un nuevo sentido a través de un acto de reapropiación y reinterpretación videolúdica que contribuye a una cierta gamificación de tales espacios. Este tipo de intervención contribuye a un nuevo mirar lúdico en el que los espacios gamificados se perciben e interpretan de otra manera, sacudiendo nuestra visión cotidiana del letargo en el que se encontraba y otorgándole un nuevo sentido lúdico y juguetón. De hecho, los mosaicos de Invader se han hecho tan populares que son muchas las personas, entre ellos muchos turistas, que se dedican a buscar, localizar y fotografíar sus piezas en diferentes ciudades, una especie de reactualización del clásico ¿Dónde está Wally? en el mundo físico y que también es posible observar en muchas de las fotografías de Invader diseminadas por la web, en las que el ejercicio de localizar el punto concreto en el que se encuentra el mosaico (especialmente en fotografías de lugares muy concurridos o con muchos elementos alrededor) constituye una práctica visual lúdica del tipo ¿Dónde está Invader?, como ocurre en la siguiente imagen:

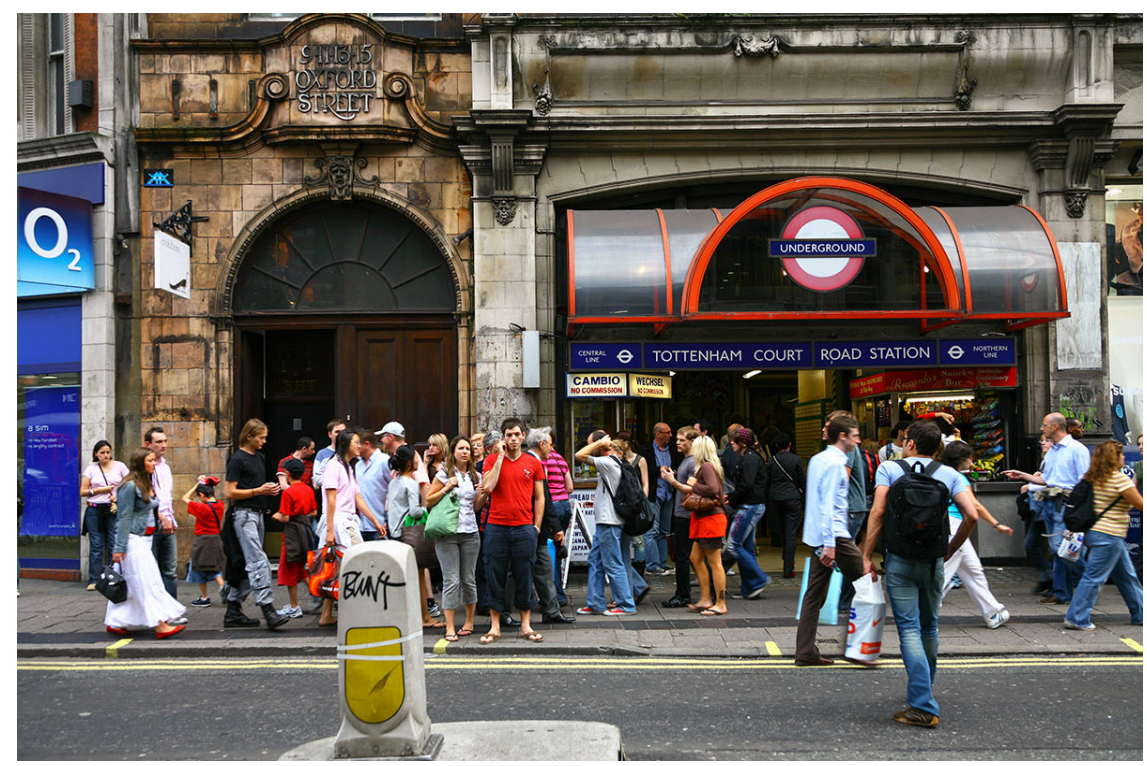

Imagen 2. Intervención de Invader en Londres.

Fuente: http://space-invaders.com/world/london/ [02/02/2019]

5 El término "gamificación" es un neologismo procedente del vocablo inglés "game" y se usa para referirse a la implementación de mecánicas de juego en entornos no lúdicos con el fin de atraer usuarios y mejorar su motivación, concentración, esfuerzo y compromiso. Para una discusión sobre los orígenes, definición y características de la "gamificación” véase Deterding et al. (2011). 
Sobre el ejercicio de localizar las piezas de Invader, el propio artista viene confeccionando desde el año 2003 diferentes mapas o guías de invasión en formato impreso que funcionan como una especie de "guías turísticas alternativas" que muestran el lugar exacto en el que están situados los marcianitos en cada ciudad, así como una pequeña historia contada por el propio Invader sobre cómo fue cada una de las invasiones llevadas a cabo en cada ciudad. Hasta el momento existen 24 guías de este tipo y tales trabajos ponen de manifiesto la capacidad de Invader para moverse y trabajar en diferentes espacios y formatos, desde el formato digital hasta al impreso, o su propio punto de partida: la calle.

El trabajo de Invader adquiere así una clara lógica transmediática, articulando una suerte de narrativa de la invasión que se desarrolla a través de múltiples plataformas mediáticas, tanto analógicas como digitales, y en la que "cada nuevo texto hace una contribución específica y valiosa a la totalidad" (Jenkins, 2008, p. 101). La totalidad sería aquí el proyecto de invasión ideado por Invader, un proyecto igualmente físico y digital, compuesto tanto de viejos como de nuevos medios (Manovich, 2006; Jenkins, 2008).

En este sentido, una de las últimas creaciones de Invader (un nuevo texto dentro de su particular red transmediática) es una app para teléfonos móviles denominada "Flash Invaders", la cual permite a los usuarios localizar sus obras en la calle, fotografiarlas y compartirlas digitalmente. El objetivo de la app es que los usuarios capturen los famosos mosaicos de Invader con su teléfono móvil y competir unos con otros para ver quién consigue capturar más fotos y obtener, así, más puntos.
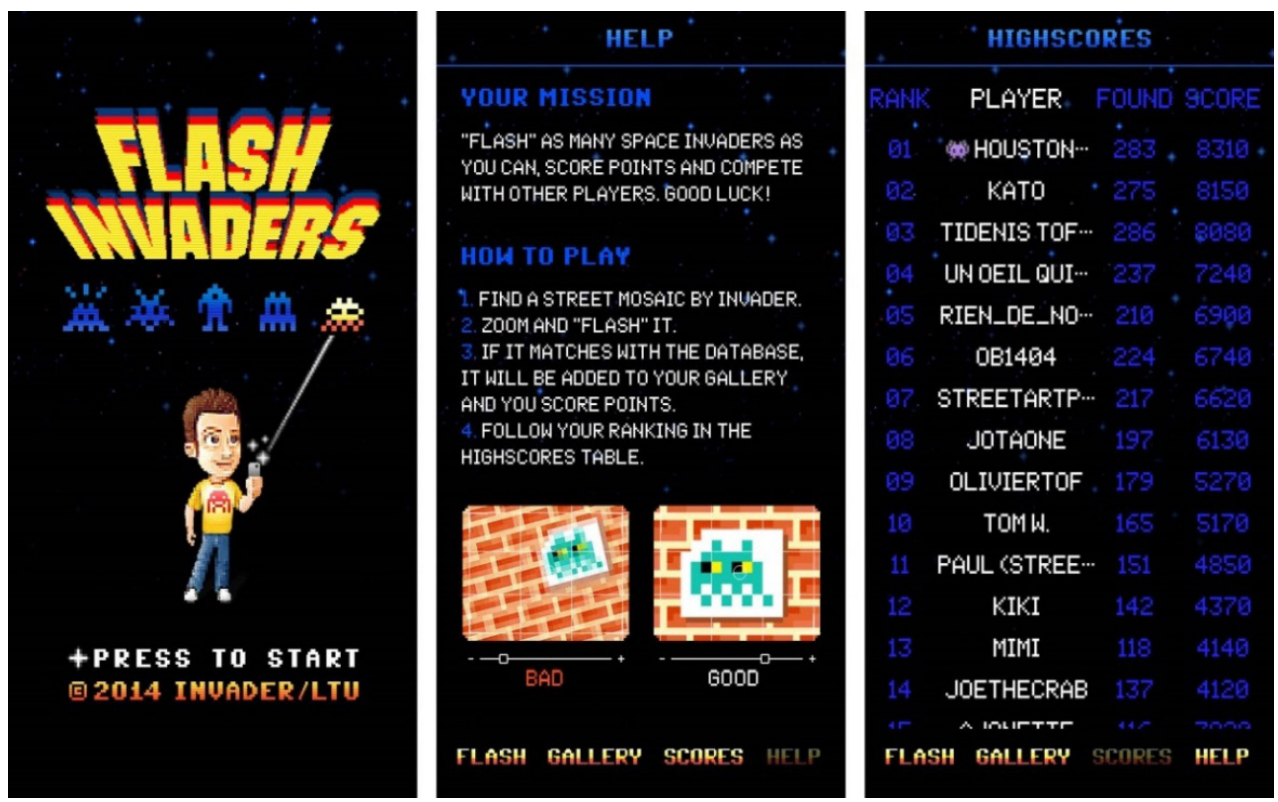

Imagen 3. Flash Invaders. Fuente: http://andberlin.com/2014/08/06/flashinvaders-a-street-artapp-from-invader/[02/02/2019] 
Mediante esta app los transeúntes devienen jugadores, pasan a ser participantes activos de la experiencia transmediática ideada por el artista francés, y juegan, compiten y se relacionan entre sí integrándose eficazmente en su narrativa.

\section{5. ¡HASTA EL INFINITO, Y MÁS ALLÁ!}

Invader es un artista (o "invasor", como él prefiere denominarse) profundamente inquieto. No contento con haber hecho de su proyecto Space Invaders una de las manifestaciones artísticas más originales del panorama actual, ha decidido llevar su invasión más allá del espacio urbano de la calle hasta alcanzar puntos difícilmente imaginables para la intervención artística. En el año 2012, Invader colaboró con el escultor británico Jason deCaires -famoso por haber creado el primer museo submarino del mundo en la bahía de Cancún (el MUSA o Museo Subacuático de Arte)- para llevar sus populares mosaicos al fondo del mar. Sus famosos marcianitos se trasladaban así del espacio urbano de la calle al mundo submarino, abriendo así una nueva fase de invasión que va más allá del espacio tradicional de la calle para abrirse a nuevos y desconocidos territorios.

Ese mismo año, 2012, Invader consiguió llevar otros de sus mosaicos al mismo espacio. El proyecto se basa en un mosaico que se lanzó a la estratosfera a través de un aparato construido a partir de un globo de helio equipado con una cámara que permitía documentar visualmente tal hazaña. Con ello, Invader consiguió crear la primera obra de arte desde el espacio y enviar (o más bien, devolver) a uno de los famosos marcianitos de Space Invaders a su lugar de procedencia: el espacio exterior.

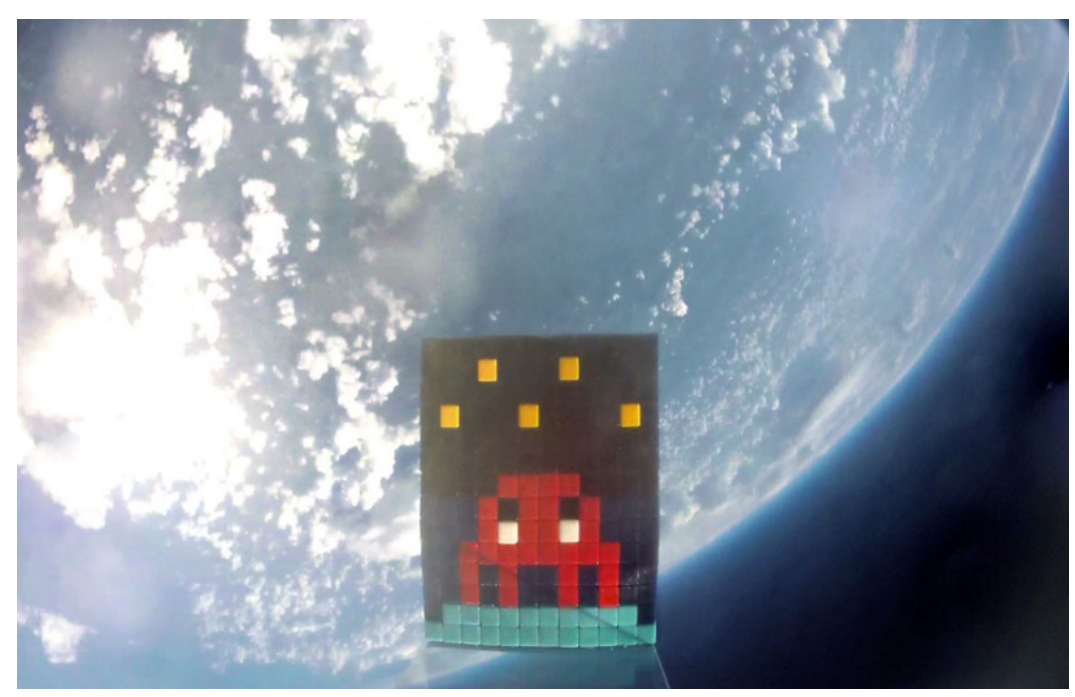

Imagen 4. Invader en la estratosfera

Fuente: http://space-invaders.com/post/ART4SPACE/ [02/02/2019] 
Ambos proyectos suponen una nueva vuelta de tuerca al fenómeno del street art, ya que dejan de estar limitados al espacio urbano para abrirse a nuevos espacios que poco tienen que ver con el universo callejero, como el mundo subacuático o la misma estratosfera. ¿Cabe seguir hablando, en estos casos, de street art? Con este tipo de intervenciones acuáticas y estratosféricas, Invader es uno de los pocos artistas callejeros que han logrado llevar la práctica del street art más allá del espacio urbano, complejizando aún más un término ya de por sí "escurridizo" (Amstrong, 2019 , p. 11) cuyos elementos definitorios cambian y se negocian constantemente (Bengtsen, 2014; Fernández Herrero, 2018).

\section{GONGLUSIONES}

“EEl juego no ha terminado!” Invader

A lo largo de este artículo hemos analizado las relaciones entre street art y videojuegos tomando como ejemplo el caso del artista parisino Invader, cuyo proyecto Space Invaders constituye una de las propuestas artísticas más interesantes y arriesgadas del panorama actual. Aparte de ser uno de los negocios más lucrativos de la actualidad, los videojuegos forman una parte importante de la cultura contemporánea y ocupan un lugar cada vez más destacado en el imaginario social de mucha gente. De ahí que muchos de sus personajes, desde Mario Bros hasta los famosos marcianitos de Space Invaders, hayan adquirido en la actualidad un estatus similar a otros personajes destacados de la cultura massmediática como Mickey Mouse, Superman o Batman.

Partiendo de la idea de que los personajes de Space Invaders son los iconos perfectos de nuestro tiempo (un tiempo en el que los videojuegos y las tecnologías digitales son el latido de nuestro mundo), Invader ha conseguido construir su identidad como artista a través de un curioso ejercicio de reapropiación y resignificación de estos personajes y sus característicos pixeles. Esto lo hace a partir de la manipulación de azulejos para formar mosaicos que "remedian" de forma material la pixelización y la estética $\wedge$ bits inherente a los primeros videojuegos. En este sentido, el proyecto artístico de Invader resulta paradigmático a la hora de analizar las relaciones entre street art y videojuegos, dos ámbitos en principio no muy relacionados, pero que gracias al trabajo de artistas como este adquieren una nueva significación y ofrecen nuevas e interesantes conexiones entre medios y artes en una era de permanente transmediación y remezcla.

Al trasladar los famosos marcianitos del videojuego Space Invaders del espacio videolúdico de la pantalla al espacio público de las ciudades Invader ha conseguido crear una especie de semiosfera videolúdica, esto es, un ambiente de signos esparcidos por el espacio público e inspirado directamente en el mundo de los videojuegos (y más concretamente, en el videojuego Space Invaders). Estos signos 
videolúdicos (entendidos como signos que remiten explícitamente al universo de los videojuegos) nacen en el espacio urbano y de allí se redigitalizan para regresar al espacio digital de la pantalla, ya no en forma de videojuego, sino de fotografías y/o vídeos digitales. Invader realiza así un original movimiento de materialización y (re)digitalización que permite a los famosos marcianitos que le sirven de identidad artística salir de su videojuego original y circular y encarnarse en otros espacios, no sólo urbanos, sino también subacuáticos e incluso estratosféricos, como ponen de manifiesto los ejemplos analizados en el apartado anterior.

De esta manera, Invader va tejiendo a través de diferentes medios y en diferentes tiempos y espacios una narrativa transmediática de la invasión en la que también participan los diferentes transeúntes que fotografían, comparten y comentan sus piezas durante sus paseos cotidianos, ya sea por iniciativa propia o motivados por aplicaciones como "Flash Invaders". El caso de Invader es muy interesante, pues se trata de uno de los artistas que mejor ha sabido explorar y explotar las ventajas de la tecnología digital para el street art, no sólo para visibilizar y dar a conocer su propia obra, sino para involucrar a los propios viandantes en el proceso.

\section{BIBLIOGRAFÍA}

Abarca, Javier (2010). El papel de los medios en el desarrollo del arte urbano. AACADigital. Revista de la Asociación Aragonesa de Críticos de Arte, No. 12 , sin páginas.

Armstrong, Justin (2005). The contested gallery: Street art, ethnography and the search for urban understandings. AmeriQuests, No. 1, Vol. 2.

Amstrong, Simon (2019). Street Art. Barcelona: Blume.

Bengtsen, Peter (2014). The Street Art World. Lund: Almendros de Granada Press.

Bolter, Jay David y Grusin, Richard (1999). Remediation: Understanding New Media. Cambridge: Cambridge University Press.

Castells, Manuel (2005). La era de la información (vol. 1): La sociedad red. Madrid: Alianza.

Camper, Brett (2009): Retro Reflexivity. La-Mulana an 8-Bit Period Piece. En Perron, Bernard \& Wolf, Mark J.P. (eds.): The Videogame Theory Reader 2. Nueva York: Routledge, pp. 169-195.

Christensen, Miyase, \& Thor, Tindra (2017). The reciprocal city: Performing solidarityMediating space through street art and graffiti. International Communication Gazette, 79(6-7), pp. 584-612. DOI: https://doi.org/10.1177/1748048517727183

Darley, Andrew (2002). Cultura visual digital. Espectáculo y nuevos géneros en los medios de comunicación. Barcelona: Paidós.

De Certeau, Michel (1999). La invención de lo cotidiano. México: Universidad Iberoamericana. 
Deterding, Sebastian; Dixon, Dan; Khaled, Rilla; y Nacke, Lennart (2011). From game design elements to gamefulness: defining 'gamification'. Proceedings of the 15th International Academic MindTrek Conference, pp. 9-15.

Eco, Umberto (1990). Semiótica y filosofía del lenguaje. Barcelona: Lumen.

Fernández Herrero, Emilio (2018). Origen, evolución y auge del arte urbano. El fenómeno Banksy y otros artistas urbanos. Tesis Doctoral. Universidad Complutense de Madrid.

Ganz Nicholas (2004). Graffiti World: Street Art from Five Continents. New York, NY: Harry N. Abrams.

García Canclini, Néstor (1990). Culturas híbridas. Estrategias para entrar y salir de la modernidad. México: Grijalbo.

Irvine, Martin (2012). The Work on the Street: Street Art and Visual Culture. En http://faculty.georgetown.edu/irvinem/articles/Irvine-WorkontheStreet-1.pdf [10/08/2019].

Jenkins, Henry (2008). Convergence Culture: la cultura de la convergencia de los medios de comunicación. Barcelona: Paidós.

Kinder, Marsha (1991). Playing with Power: From Muppet Babies to Teenage Mutant Ninja Turtles. Berkeley, CA: University of California Press.

Kohler, Chris (2016). Power-up: How Japanese Video Games Gave the World an Extra Life. Mineola, New York: Dover Publications.

Lipovetsky, Gilles (2002). La era del vacio. Ensayo sobre el individualismo contemporáneo. Barcelona: Anagrama.

López, Ángela (1998). El arte de la calle. REIS. Revista Española de Investigaciones Sociológicas, n. 84, pp. 173-194.

Manovich, Lev (2006). El lenguaje de los nuevos medios de comunicación. La imagen en la era digital. Barcelona: Paidós.

Márquez, Israel; Tosca, Susana (2017). Playing with the city: street art and videogames. Arte, individuo y sociedad, ISSN 1131-5598, vol. 29, n. 1, pp. 105-120. DOI: https://doi.org/10.5209/ARIS.51892

Mirzoeff, Nicholas (2003). Una introducción a la cultura visual. Barcelona: Paidós.

Pérez-Gómez, Miguel Ángel (2009). El culto al pixel: una aproximación al retrogaming como forma de fandom. Comunicación, vol, 1, n. 7, pp. 222-234.

Reinecke, Julia (2007). Post-Graffiti: Between Street, Art and Commerce. Hamburgo: Gingko Press.

Ryan, Jeff (2011). Super Mario: How Nintendo Conquered America. New York: Portfolio/Penguin.

Urry, John (2005). The Complexities of the Global. Theory, Culture and Society, v. 22, n. 5, pp. 235-254. DOI: https://doi.org/10.1177\%2F0263276405057201 